\title{
Identification of Key Characteristics for Knowledge Commerce in Globalization Era
}

\section{Mohammad Reza Ebrahimi Seighalan*}

Faculty of Management, Multimedia University, Jalan Multimedia, 63100 Cyberjaya, Selangor, Malaysia

E-mail: engebrahimi@yahoo.com

*Corresponding author

\section{Mohd Nor Ismail}

Faculty of Management, Multimedia University, Jalan Multimedia, 63100 Cyberjaya, Selangor, Malaysia

E-mail: mohdnor.ismail@mmu.edu.my

\section{Norizzati Azudin}

Faculty of Management, Multimedia University, Jalan Multimedia, 63100 Cyberjaya, Selangor, Malaysia

E-mail: norizzati.azudin@mmu.edu.my

\begin{abstract}
Exploiting knowledge for more financial profit is a development born out of the recognition of knowledge as the most critical resource for any size of organization, where all types of knowledge are deliberately or serendipitously generated, recorded and retained. However, the usage of the Internet as the main vehicle in disseminating market and knowledge in knowledge commerce is fairly new. The purpose of this paper is to describe the pros and cons of knowledge commerce in organizations, by analyzing their major characteristics. The paper also proposes Knowledge Commerce Phases which will help to determine the most beneficial point to initiate the commercialization of knowledge in an organization.
\end{abstract}

Keywords: Knowledge commerce, globalization, intellectual property, knowledge management.

Biographical notes: Mohammad Reza Ebrahimi is currently a SAP Consultant and Corporate Strategic Planner of PLUSXPERT Sdn Bhd. He holds various operational and corporate management responsibilities - particularly in branding and positioning, partners and clients development, local and international marketing, sales and corporate strategic planning. Reza has served the AJV Group of Companies as Sales and Marketing Consultant and Project Coordinator - in charge of hypermarket management, strategic planning, market analysis, research and development. Prior to his continuing education in Malaysia, Reza worked with several companies in Iran, such as, Delataye Iranian Steel Industrial (PIS) Co. as Sales \& Commercial Manager and Consultant in (ISO) Quality and Innovative Management, Hicofze Co. as Quality and Commercial Management Consultant, Delta Piramid Co. as Sales 
and Marketing Manager, Azarshahr Cement Industries Co. as Control Project Manager. Besides his corporate experience, Reza published a few books and articles in the area of Industrial Engineering and Management, including the Dictionary of Industrial Engineering. He holds a B.Sc. in Industrial Engineering (1st Class) specializing in Technology Development from the University of Science and Technology, Iran and an MBA in Multimedia Marketing from Multimedia University, Malaysia. He is currently pursuing his $\mathrm{PhD}$ in Knowledge Commoditization.

Mohd Nor Ismail has a B Sc in Electrical Electronics Engineering and MBA from University of Southern California and Northrop University in Los Angeles, California, USA respectively. He served the Sapura Group of Companies - a local multi-national conglomerate for a period of 20 years, the last position being the Senior Vice President of Telecom Business Unit 3. He held various operational and corporate management responsibilities particularly in Quality Management, Manufacturing, Contract Management, Vendor Development, Business Development, International Marketing and Sales and Distributions. He also served at Puncak Niaga Sdn Bhd as Special Assistant to the Executive Chairman in charge of Business Development. He is currently employed as Specialist in Management with the MMU Faculty of Management. Besides teaching, he is also an active researcher and involved in several committees in the university.

Norizzati Azudin has a Bachelor of Arts (Hons) with Major in Media Studies and Minor in South East Asian Studies from Universiti Malaya (UM). She served Multimedia University (MMU) as Assistant Manager for four years while pursuing her Masters in Science (Corporate Communication) from Universiti Putra Malaysia (UPM). She has several years of experiences working as Part Timer for Radio DJ for Radio Television Malaysia Penang (RTM), Sistem Television Malaysia Berhad (TV3) and a part time teacher. She has been a lecturer in Multimedia University (MMU) for four years. She was the Assistant Head of Management Department under the Faculty of Management, Assistant Coordinator of BBA programme, University Student Affairs Committee Member, and Self Appraisal Committee Member. She is an active researcher with several papers published every year. Besides, she is an active trainer for both MMU and other corporate organizations. She is currently on study leave, pursuing her PhD in International Communication and Trading.

\section{Introduction}

In the last three decades, many researchers and literatures have discussed Knowledge Management (KM) and its usage for companies to gain competitiveness (Charles Despres and Daniele Chauvel, 1999). Despite all these endeavors to spread the deployment of KM, almost no research for commercializing of knowledge has been published until now. Before going on, we should delineate our terms. There are many definitions for knowledge. We adapt the following definition of knowledge, based on the work of Nonaka et al., 2000), Liebeskind (1996, p.94) - Knowledge is the outcome of justifying validated information, proven experience, and personal belief towards the truth. There are other components for knowledge such as skills, culture, character, feelings (R.P. uit Beijerse, 2000) but in this paper we will look at knowledge by the manner defined above. After identifying the definition of knowledge, we can define knowledge management. Many definitions of KM also exist in the KM literature. The most concise among them are the ones developed by Bassie (1997, p.25), Martinez (1998, p.89), Alavi and Leidner 
(1999) which we utilize for expressing our own definition. We define knowledge management as the process of generating, recording, retaining, organizing, evaluating, transforming, disseminating, and leveraging of intellectual assets to enhance organizational performance. Most of the companies that strive to accomplish all these time- consuming and tough practices but are not aware of other benefits of this "newly emerging interdisciplinary business model" (Ruggles, 1998) are engaged in inefficient knowledge collecting. Knowledge other than internal utilizations can also be used for external environments with the intention to distribute it wherever it can assist to create the biggest payoffs (Blake, 1998, p.12). According to the reasons mentioned above, there is a need to elaborate the relatively new concept of knowledge commerce. In this context, Knowledge Commerce is the commercialization of knowledge used in order to optimize the usage of an organization's intellectual capital to expand market opportunities in an era of competitiveness and globalization. In fact, "knowledge commerce" is the convergence of the most critical resource for any size of organization and the most important goal of any company "making profit" by using their assets. The emergence of extensively reachable digital market places and close competition between companies in the global market facilitates this necessity to think about other means of making money as a strategic initiative.

\section{Factors in the Emergence of Knowledge Commerce (KC):}

\subsection{The Rapid Development of Knowledge and Technology}

Nowadays new technology fills the shoes of previous technology. When this occurs, the knowledge which was utilized for old technology becomes useless. In other words, with the development and advancement of technology, the effectiveness or usefulness of old knowledge is eliminated. Thus, when people want to record, retain, organize, evaluate and transform this old knowledge, some new innovation comes and the old knowledge is gone. This incident motivates companies to go through other channels to gain knowledge faster.

\subsection{The Growing Competition between Companies and Full Efforts for Gaining Competitive Advantages}

Most companies are looking for new approaches to differentiate their own company from others. Consumer awareness always occurs via past experiences of the company's product and marketing program (Kotler et al., 2006, p.280). Commercializing knowledge as an intellectual product could be a special opportunity for the marketing departments of the companies to facilitate business development and making a difference. On the other hand, knowledge commerce can also advance the companies by enabling them to gain knowledge faster than other competitors and utilizing the knowledge as a competitive advantage.

\subsection{Knowledge Management (KM) and e-Commerce Revolution}

Implementing knowledge management within companies is becoming more familiar and most companies know how to perform and are aware of its benefits in short and long term business. Simultaneously, the necessity of using the Internet as a marketing vehicle and the emergence of e-commerce is acknowledged by most companies. Companies are 
recognizing that success in the new economy will be achieved by having the right mix of bricks and clicks and being able to execute clicks-and-mortar strategies that bridge the physical and the virtual worlds (Gulati and Garino, Harvard business review, 2000). Combining KM and e-commerce can create new prospects for companies in the global market to gain knowledge and commercialize it with the help of the Internet, i.e. eknowledge commerce approach. Thus, amalgamation of the two concepts indirectly structures the knowledge commerce base.

\subsection{Globalization (saturation of domestic market and global competition)}

"The term global epitomizes both the competitive pressure and the expanding market opportunities all over the world" (Kotabe and Helsen, 2004, p.7). Going through the global market requires vast market information about other countries, such as market structure, size of the market, market power, government policies, aggregate demand, entry and exit barriers, suppliers, competitors, average income, prices, availability of substitutes and complementary products, risks, taste and preferences, expectations, culture, environment, religion, and other information. Achieving this reliable, accurate and current information is very tough and time consuming. Knowledge about the market can be used to create new businesses and compete with established ones in same field. Therefore companies occasionally decide to purchase this information from validated resources instead of conducting their own research as part of agile strategic market penetration.

\subsection{Emergence of Collaborative Activities}

"Global competition also brings about global cooperation" (Kotabe and Helsen, 2004, p.3). As a result of collaborative activities such as joint ventures and partnerships, close competition between companies is becoming very common. These strategic alliances bring opportunities to create more competitive advantages (Bennett and Gabriel. 1999) because alliances generate the potential for firms to acquire knowledge associated with partner skills and capabilities which can then be incorporated into their own systems and structures (In-kpen, 1996, p.123). Therefore, the companies desire to leverage the intellectual assets of other companies to enhance their own organizational performance and productivity. This illustrates the nature of knowledge commerce.

\subsection{Increase in Knowledge Sharing Culture}

The definition of knowledge sharing is person to person sharing of information, opinions, proposals, and skills that are organizationally pertinent (Bartol and Srivastava, 2002). The implementation of knowledge economy for developing countries requires free and open educational resources. Most of the people in these countries are noncommercial users, so a number of companies disseminate part of their knowledge with the purpose of increasing the knowledge sharing culture and developing their economy. This phenomenon is shaping a future with old free users who are now shifting to customers with high needs. In this situation knowledge commerce will appear. 


\section{Knowledge Commerce and Value Creation}

\subsection{Enhancing Intellectual Property (IP)}

Intellectual capital (IC) comprises the intangible sources of value associated with stakeholders' relations, company's resources, operating system and worker's abilities and potentials (Kujansivu and Lo"nnqvist, 2007). Intellectual property (IP) is the collection of innovations associated with things such as patents, authorship, copyright, inventions, trademarks, designs, trade secrets, and trademarks which are easier to value and being the most tangible element of IC (Kotabe and Helsen, 2004, p.160; Bollen et al, 2005).

In this paper we assume IP as part of the relation among IC and company performance based on the work of Bollen et al. (2005). Intellectual property (IP) in present knowledge based economy is becoming the critical strategic asset of any organization, serious driver of innovativeness, and a vital source of competitive advantage whereas economies rely more on tangible assets such as land and capital in the past (Grant, 1997; Beijerse, 1999; Teece, 2000; Nonaka et al., 2000; Marr et al., 2003). Implementing knowledge management on its own does not increase the profit of the company; it just enhances the intellectual asset. However, if you cannot sell knowleedge and convert it to money, it does not have any economical benefits for the company. Most companies are not aware of the value of their knowledge because they cannot distinguish, envisage and evaluate the critical IC as being crucial for the performance of their organization (Roos et al., 1997 and Marr et al., 2003). From the commercialization point of view, probably they do not know how to segregate their intellectual assets, how to value them, and how; when; where; and to whom to sell the intellectual assets. Solving these ambiguities which exist in commercializing the knowledge can help these companies create value and increase their assets. In addition, the purpose of knowledge commerce is not just about trading IP directly and making money for the company. The purpose also includes organizing and sharing knowledge, and promoting the building, sustaining, augmenting and preserving of brands, which is the most unique function of professional marketers to make more profit for the company (Kotler et al., 2006, p.279). By means of making brand image, and forming strong customer value, satisfaction and loyalty, marketers are able to assist their companies in increasing their intellectual property, gaining more customers, and finally achieving the main goal of the companies. This will consequently lead to a boom in the net worth and profit of the company.

\subsection{Strengthening the Linkage between Manufacturing, Marketing, and $\mathbf{R} \& \mathbf{D}$}

Generally, technology is defined as the science of know-how. It can be classified as "product technology" - the practical knowledge and ability for production and for manufacturing a new product; and "process technology" - the action of combination of some new resources for producing finished goods. Product technology may not give a competitive advantage to the companies in the long run except "it is matched with sufficient manufacturing capabilities" (Kotabe and Helsen, 2004, p.308). On the other hand, good marketing has increasingly grown to be the fundamental component for successful businesses or in other words, marketing is "meeting needs profitably" (Kotler et al., 2006, p.4). The marketing department of a company needs knowledge about the customers and their priorities, competitors resources and technologies, manufactured 
goods and services, distribution channels, suppliers, organization's practices and other useful information (Bennett and Gabriel, 1999).

In the current market, the terrific force of offering more innovative and different products make $\mathrm{R} \& \mathrm{D}$, the vital element of most business activity. So, linking Manufacturing, Marketing, and R\&D endow huge advantages to businesses in an extremely competitive market directly or indirectly (Kotabe and Helsen, 2004, p 308). Cost and time which are needed to create knowledge is much higher than gaining knowledge from less difficult channels and taking it on for their own usage. There are several methods for acquiring the knowledge such as imitation, replication, and substitution (Ganesh D. Bhatt, 2000). However, in knowledge commerce we are looking at the commercialization of this knowledge. $\mathrm{KC}$ can also reduce the cost of obtaining new resources for manufacturing and doing research and development (R\&D) for the optimization of the manufacturing and operational process and simultaneously helping the marketing department to gather essential knowledge for competing in the market place. Knowledge commerce can set aside time and attempts to get access to knowledge. Thus we can say implementing knowledge commerce can increase the competitiveness of an organization by optimizing cost and time.

\subsection{Increasing the Ability for Comparison and Making Better Decision}

There are so many definitions for the word "decision". We accept the following definition of a decision: "A decision is defined as a moment, in an ongoing process of evaluating alternatives for meeting an objective, at which expectations about a particular course of action impel a decision maker to select that course of action most likely to result in attaining the objective" (Harrison, E.F., 1995). With this definition of a decision, we can define decision making by using Herbert A. Simon's definition:

"Decision making comprises three principal phases: finding occasions for making a decision; finding possible courses of action; and choosing among courses of action" (Simon, H.A., 1960). From the definition above, we can comprehend that decision making is about differentiating between pertinent decisions, in which the decision maker selects the favored purpose, the mainly logical mission statement, or the superlative functions (Emory, C.W. and Niland, P., 1968). In this situation, comparison is very rational for making better decision. In fact, when you compare your own information with other companies or data bases, you can discover your own weaknesses, strengths and opportunities, instead of just looking at your own historical data. In other words, by utilizing the $\mathrm{KC}$ concept your resources will be optimized. This means that you can allocate less time to produce, record, retain and organize, and put more effort in evaluating and transforming by doing comparative research and development on your own and others' knowledge.

\subsection{Assisting the Growth of Collaborative Activities}

With the emergence of the internet and globalization era, businesses are under pressure to meet progressively more superior service level expectations. Satisfying customers is becoming a big deal. Companies around the world are looking for ways to enhance the service level to provide a situation to establish collaborative activities to solve this serious problem. Collaborative businesses allow companies to work together any where, any time and in any field more efficiently. 
However, the problem is a number of small and medium enterprises that may not have the affordability to participate in the global marketplace by "exporting, joint venture, or direct investment". The lack of adequate financial resources persuades enterprises to internationally license their intellectual property with the purpose of enlarging their businesses and then contribute in the international competitions (Kuratko and Hodgetts, 2007, p642). Licensing is basically a feasible and economical technique or tool for commercializing knowledge that will help any size of organization to put their experiences and knowledge in the market.

Therefore, we can conclude that knowledge commerce is encouraging collaborative activities to take place.

\subsection{Preventing Organizations from Losing the Accumulated Knowledge}

There are three points of views for losing the knowledge:

During the research and development period, companies congregate some extra knowledge whereby after implementing the project or producing the final goods, remains useless. So this knowledge which was not being used directly in the production or implementation process can be packaged and sold in other markets.

With the entrance of new technology, older knowledge will become obsolete. So by looking at knowledge commerce life cycle we can realize approximately how much time we have to sell the knowledge and during which period would the best time to fully utilize the knowledge value. For example, software producer should roughly know how long they can survive, how difficult is it for other competitors to duplicate their product and what are their core benefits. By leaning on this, they can remain in the market place.

Knowledge commerce may be concerned with reusing the out-dated technology which companies can modify. In this case, useless knowledge can be recycled and further commercialized. This means perishable knowledge can be converted to recyclable knowledge, thereby, increasing the return on their investment in improving old technology, and revitalizing it.

\section{Destructive Side of Knowledge Commerce}

Besides the advantages that exist for knowledge commerce, there are obstacles for the intellectual property initiator due to the advent presence of e-commerce and the information age. Businesses necessitate being aware of ruin and business continuity by protecting their knowledge as an intellectual core competency of their business. IP which used to be "unfungible: difficult to replace one item with another" is becoming easily substitutable as a result of imitable characteristics of most of the information. So it is effortless to copy, imitate and reproduce the contents in new works or even the same works. Any part of "electronically represented intellectual property" is possible to be duplicated anywhere around the world by using the Internet. But increasingly valuable creations in developed countries originate from the commercialization of such "information-based intellectual properties". So, these countries are keen on enforcing stricter global laws governing intellectual property such as patents, copyrights and trademarks (Kotabe and Helsen, 2004, p.48-49). In addition to these IP rules, some decision making are play an important role in commercializing the knowledge. 


\subsection{Selling Knowledge to Inappropriate Interested Parties}

Selling knowledge to inappropriate people leads to stronger competitors. Choosing buyers could be a very significant part of decision making in commercializing knowledge assets. Precise research on the purchaser is vital in this part, unless the company is a consulting agency and in this case the only probable losses are monetary, not the future of the company. Thus, companies should perform a multi-purpose evaluation and assessment to recognize their best prospect customers in order to avoid any losses. Methods for finding safe prospect customers will be presented in this paper.

\subsection{Selling Knowledge with Reduction of the First Value of Knowledge}

Selling knowledge means sharing professions, secrets, experiences, practices with other business partner whether competitor or not. Although there are financial benefits in this transaction but as a result of characteristic of intellectual properties, selling equals to loosing. Competitors are able to plagiarize your knowledge and sell it with higher price. That is the reason why companies should identify and properly save their core competencies, and emphasize on licensing or choose an appropriate purchaser.

\subsection{Price Chiseling}

Intangibility of knowledge assets separates it from value system. Since there is no price ceilings and floor, seller can offer any price and it is very hard to set a price and control it. Thus in situations where there is no price stability, the buyer should be completely priceconscious. On the other hand, increase in the price levels motivate companies to license and commercialize their knowledge assets deliberately. So it will be quite hard for small and probably medium enterprises with lower capital to compete and survive.

\section{Phases of Knowledge Commerce}

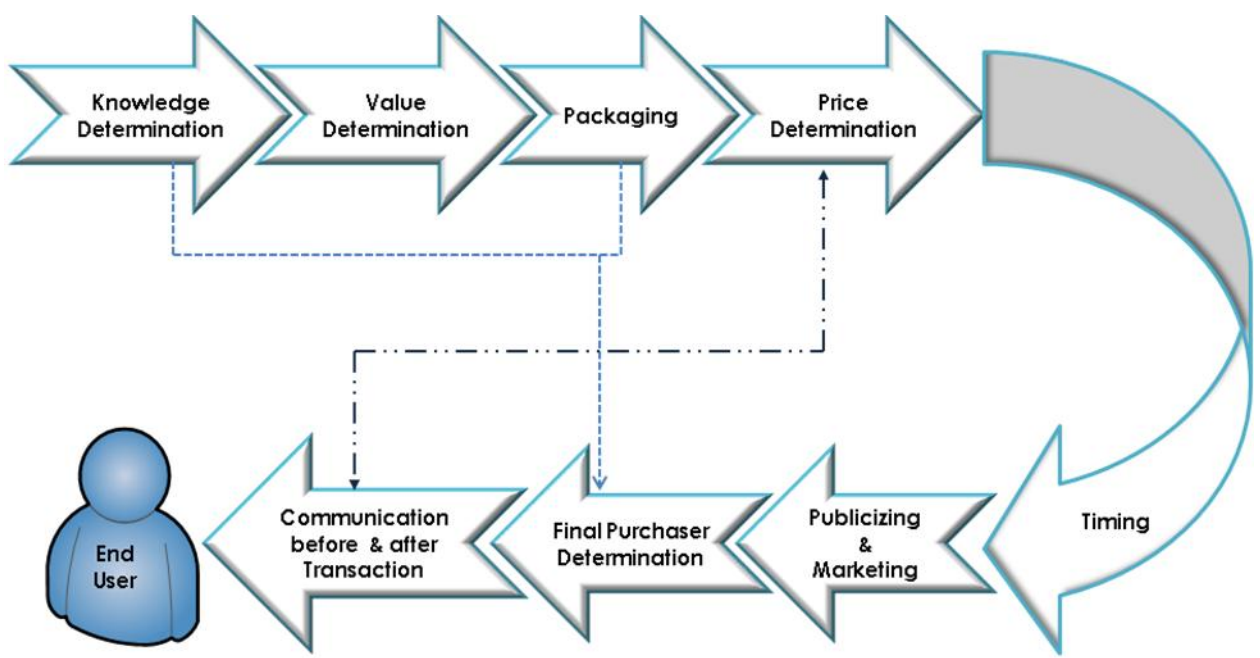

Figure 1. Knowledge commerce phases

Buying or selling knowledge is close to trading a business or service. Consequently we are using the critical attitudes of businesses and services for assessment. We consider 8 
Phases for knowledge commerce that can be useful for making better decision (see figure $1)$.

\subsection{Knowledge Determination}

The first and critical phase for company to commercialize their knowledge is knowledge determination. Different authors categorize knowledge property in different ways. We used the following classifications for knowledge determination. Companies should exactly know what kind of intellectual capital exists in their companies that generate benefit. Nonaka (1995) categorizes knowledge into explicit and tacit which are the most accepted forms of knowledge classification. Explicit knowledge can be articulated and codified in forms of data, formula, stipulations and best practices (Alter, 2002). Tacit knowledge can be expressed as practical insights, perceptions acquired by specialist and it is difficult to formulate and represent (Crowley, 2000). Usually explicit part of the knowledge is more possible to sell because you can illustrate, touch or experience it. But unfortunately a large portion of knowledge is tacit and tacit knowledge is invisible and intangible and is under the water, based on the "iceberg analogy" of Abdulai (2004). Knowledge assets might be comprised of "stakeholder resources, human resource (skills, know-how, competences, etc.), stakeholder relationships (customer relationships, licensing relationships, distribution relationships, etc.) and structural resources, virtual infrastructure (culture, routine and practices, intellectual property) (Marr et al., 2002). These determinations can assist companies in order to distinguish between types of intellectual property which exist inside the organization.

\subsection{Value Determination}

Subsequent to identifying the knowledge is determining the value of intellectual capital. Since intangible assets like patent or trademark have no physical existence it seems to be invaluable but actually it can be very valuable (Ross et al., 2005, P.22). To recognize the value of particular intellectual capital, companies should determine which of these capitals are yielding positive return, or being the core competency which companies are not able to survive without. At this phase, management decision is very critical to modify or destroy the future of the company. Value determination is one of the most important parts of knowledge commercialization. For this, we should look at some characteristics like inimitability, the complicatedness of duplicating and imitating for competitors and internal company's potential for expansion. What is the importance of certain intellectual capital in order to compete productively? Durability is the expected life of special intellectual property, while uniqueness is the ease of substituting with an alternative. Non-transferability is the complexity for buying and selling freely in the marketplace. There are questions which occur before decision making process and all are essential for both buyer and seller.

\subsection{Price Determination}

The next phase after determining the value of a product is pricing. Price is the only part of the marketing mix which generates revenue. Thus pricing decision is one the essential and critical phase for the existence of any businesses that is very multi-faceted and complicated and should agree with the company's marketing, target market and brand positioning strategies (Kotler et al., 2006, p.451). Setting price is one of the prior steps while introducing a new product. Consciousness of price elasticity of demand and supply, 
price homogeneity, price responsiveness, price stability, price sensitivity and other pricing policy can play a vital role in price expectation. Although such pricing strategies have been developed, including cost-oriented pricing, competition-oriented pricing (Zeithaml, Parasuraman and Berry, 1985) but the way which we suggest for intellectual property is demand-oriented pricing which Yelkur \& Herbig (1997) used for pricing of services and called it as differential pricing. In this method, companies must take five steps to attain the price which comprises of choosing the target market, segmenting the customers, estimating the demand for each segment, indicating the willingness to pay for each customer, determining the price (see, Yelkur \& Herbig (1997) for an elaborate discussion).

\subsection{Packaging}

After setting the price, the next phase is packaging. Packaging is defined as the knowledge and technology of keeping products in a safe package by the purpose of containment, maintenance, transportation, storage, and customer attraction and information display (Lee and Lye, 2003). Knowledge products usually codify and package in forms of computer software, articles, databases, expert systems, books and so on. Different authors look at particular effects of packaging like logistics, marketing and storing. In this paper, we highlight the information display in order to position the product as a marketing method. Information that we try to convey to the customer as an introduction of package is directly related to sales packaging, product awareness, strengthening the product's image (Prendergast and Pitt, 1996). So these information should be comprehensive, attractive, segregated and accurate so as to ensure customers can make certain and correct decision about the product. This is in contrast to choosing the package accompanied by uncertainty, risk, pleasure less and ambiguous. Evans and Berman (1992) mention that packaging is a product possession or feature but Olson and Jacoby (1972) describe packaging as the extrinsic element of the product. Underwood (2003) on the other hand presents it as part of the purchasing and consuming procedure. Keller (1998) also believes that packaging is an attribute which is not concerned with the product. However, we should remember that intellectual products are not evaluated similar as physical products in the mind of customers as a result of intangibility. Thus the package of an intellectual capital should contain such information which also enables it to position itself in the mind of the customer. Positioning relates to functions which are created in the minds of the prospect customers and influencing in a way that leads to the successful purchase.

\subsection{Selling or Buying Time}

Time is also a significant aspect to determine how quickly a new idea can be converted into knowledge business and when approximately companies should offer their packages as a result of uncertain situations for demand in company's production decision making process in these unstable and doubtful times (Desai et al., 2007). Thus, analyzing the market before deciding the time for publicizing can clarify the true market value of the package. Companies often think to sell their property when it does not have any usage and attraction. But companies should know that this is the worst time to sell due to the value from the purchaser's point of view. In other words, the best time is after finding and proving the viability and validity of another knowledge property before the old ones expire completely.

Choosing the time also depends on the nature of property. Kotler et al. (2006, p.335) categorized products based on their life cycle to three groups. "Style", products 
which will remain for generation and we can assume them similar to some kinds of basic knowledge such as mathematics, chemistries, etc. which almost never perish. "Fashion" is product which is currently approved by the people which can assume similar to some kinds of software and technology which will be acceptable until it can provide the needs and after new technology coming in the market they will be perish. "Fad" is fashions which come speedily to the market with huge enthusiasm and after a while turn down quickly which we can assume similar to new ideas and thesis that attract so much attention but can be rejected very fast due to some reason or other. So we can find the knowledge property's characteristics the same as physical products and companies can recognize and predict their knowledge life cycle by this categorization.

\subsection{Publicizing and Marketing Determination}

Publicizing is the next step after realizing the best time to commercialize the knowledge. In order to sell the knowledge package and at a significant price, companies need accurately sell strategy and appropriate marketing plan. In this part, choosing the correct place for publicizing and marketing your product is very important. Companies such as "Outokumppu", "Mackinsey", and "Thomson" that use this approach use the Internet as their marketing vehicle. The utilization of the Internet as a worldwide accessible network to disseminate, market and sell the knowledge and the speedy acceptance of the Internet in a short time compared to other technologies such as the telephone and the personal computer results in greater market reach. Thus, nowadays companies use internet for identifying and initiating their investment in all fields, researching, proliferating and managing its spread (Feher and Towell, 1997). Another issue for any type of marketing is the advertising matter which for internet marketing, companies should be able to create powerful and effective internet advertisements, attractive and brief but comprehensive mail and licensing their old or even new ideas and sell or lease them to others in or out of their fields of business who can take advantage from that knowledge.

\subsection{Final Prospective Purchaser Determination}

Finding the right purchaser is one of the critical parts of knowledge commerce process. There are some knowledge organizations such as "Outokumppu", who generates new revenue from its available knowledge; "Mackinsey", who records, retains and disseminates individual's tacit knowledge; and "Thomson", who patents, sells and denotes intellectual property to generate revenue and create value for their clients by their knowledge repositories. There are two points to consider in finding the prospective customers, the first is the difficulties in recognizing who are the prospective customers. In this part, those companies look at their resources and its capabilities; besides identifying who can gain maximum value from their resources. The second point of view which is also critical is finding and selling to the right customers. Selling knowledge in two special areas or groups of companies may not cause so many problems for companies. They can license or educate their knowledge to other people in their type of business, but in non-competitive geography area, for example, in countries or continents where there is no threat to their private territory. They also can propose their knowledge to companies which operate outside of their field of business whose sales opportunities might be enlarged by utilizing their practices. For instance, manufacturing companies could modify and package their unused knowledge which was gained during the production process and sell it to other consulting company in or out of their fields. This is to utilize it for recommending better solutions so that more revenue can be generated, and more 
value can be increased for their shareholders. The important issue here is recognizing the prospect customers who can benefit from their knowledge and finalizing the best ones.

\subsection{Communication before and after the Transaction}

One of the important issues which exist in knowledge commerce is communications before and after transaction. Intangibility characteristic of knowledge product make it risky; customers are not able to evaluate it before making decision to purchase. Therefore, the risk of "needs match", the package of knowledge is not able to fulfill the actual needs of purchaser as a result of uncertainty on details of it and risk of 'service delivery'; the services which were promised in terms of guidance and instructions. This will fulfill the customer's expectations. In this case, a large amount of perceived value by the customers depends on the background information which is presented to the customers. This is to embrace it and guarantee for services after sales in order to assure their purchases. Superior services can motivate customer to take higher prices and pursue the package purchase. In other words developing business may rely directly on "pre-sale" information for convincing and assuring the customer for fulfilling and satisfying their exact needs and "post-sales" service delivery for fulfilling their expectations later (Growth,1995).

\section{Conclusion}

It is therefore very clear that Knowledge Commerce is a viable venture in itself both from the perspective of Tangible and Intangible benefits to the organizations. We have seen factors in the emergence of $\mathrm{KC}$ such as, rapid development of knowledge and technology, growing competition and enhanced competitive advantage, revolutionizing of ecommerce and KM, globalization, strategic alliances, and increased in knowledge sharing culture.

From the view of value generated from such KM, we can see IP enhancement thereby promoting innovations and creativity, strengthening of cross functional activities, effective decision making, value driven collaborative activities, and preventing the loss of accumulated knowledge.

Nevertheless, the destructive side of $\mathrm{KC}$ includes the challenges surrounding the end user profile, destroying the value of the previous knowledge and also no control of price chiseling.

The phases of $\mathrm{KC}$ includes first how to determine knowledge, how to determine value, packaging, price determination, timing, marketing and promotions, determination of end user, and communications before and after the transaction.

Further to this, the authors shall continue identifying clusters of organization on which field research can be conducted to further expand the factors and barriers influencing $\mathrm{KC}$, and other areas that may be of general and specific interest.

\section{References}

1 Alter, S. (2002), Information Systems: The Foundation of E-business, 4th ed. Pearson Education, Upper Saddle River, NJ.

2 Beijerse, R. (1999). Questions in knowledge management: defining and conceptualizing a phenomenon. Journal of Knowledge Management, 3(2), 94-110. 
3 Bennett, R. \& Gabriel, H. (1999). organizational factors and knowledge management within large marketing departments: an empirical study. Journal of knowledge management, 3(3), 212-225.

4 Bhatt, G.D. (2000). Organizing knowledge in the knowledge development cycle. Journal of knowledge management, 4(1), 15-26.

5 Bollen, L. Vergauwen, P. \& Schnieders, S. (2005). Linking intellectual capital and intellectual property to company performance. Management Decision, 43(9), 11611185 .

6 Crowley, B. (2000). Tacit knowledge and quality assurance: bridging the theorypractice divide. In Srikantaiah, T.K. and Koenig, M.E.D. (Eds), Knowledge Management for the Information Professional, Information Today, Medford, NJ, 205-220.

7 Davenport, T. H. (1994). Saving IT's soul: Human-centered information management. Harvard Business Review, 72(2), 119-131.

8 Dearden, J. (1978). Cost accounting comes to service industries. Harvard Business Review, 56, September-October, 132-140.

9 Desai, P. S., Koenigsberg, O. \& Purohit, D. ( 2007). The Role of Production Lead Time and Demand Uncertainty in Marketing Durable Goods. Management Science, 53(1), 150-158.

10 Emory, C.W. \& Niland, P.(1968). Making Management Decisions. Houghton Mifflin, Boston, MA, 12.

11 Feher, A. \& Towell, E. (1997). Business use of the Internet. Internet Research: Electronic Networking Applications and Policy, 7(3),195-200.

12 Groth, J. (1995). Important factors in the sale and pricing of services. Management Decision, 33(7), 29-34.

13 Harrison, E.F.(1995) The Managerial Decision Making Process, 4th ed. Houghton Mifflin, Boston, MA, 4.

14 Keller, K.L. (1998). Strategic Brand Management. Prentice-Hall, Upper Saddle River, NJ

15 Kotabe, M. \& Helsen, K. (2004). Global Marketing Management, 3rd ed. John willey \& Sons, Inc.

16 Lee, S.G. \& Lye, S.W. (2003). Design for manual packaging. International Journal of Physical Distribution \& Logistics Management, 33(2), 163-189.

17 Lovelock, C. (1981). Why marketing management needs to be different for services. In Donnelly, J.H. and George, W.R. (Eds), Marketing of Services, American Marketing Association, Chicago, IL, 5-9.

18 Nonaka, I. \& Takeuchi, H. (1995). The Knowledge-Creating Company. Oxford University Press, New York, NY.

19 Nonaka, I., Toyama, R. \& Nagata, A. (2000). A firm as a knowledge creating entity: a new perspective on the theory of the firm. Industrial and Corporate Change. 9(1), $1-20$.

20 Olson, J.C. \& Jacoby, J. (1972). Cue utilization in the quality perception process. In Venkatesan, M. (Ed.), Proceedings of the 3rd Annual Conference of the Association for Consumer Research, Association for Consumer Research. Iowa City, IA, 167-79. 
21 Prendergast, G. \& Pitt, L. (1996). Packaging, marketing, logistics and the environment: are there trade-offs?. International Journal of Physical Distribution \& Logistics Management, 26(6), 60-72.

22 Simon, H.A.(1960). The New Science of Management Decision. Harper \& Row, New York, NY.

23 Underwood, R.L. (2003). The communicative power of product packaging: creating brand identity via lived and mediated experience. Journal of Marketing Theory and Practice, 11(1), 62-76.

24 Yelkur, R. \& Herbig, P. (1997). Differential pricing for services. Marketing Intelligence \& Planning, 15(4), 190-194.

25 Zeithaml, V.A., Parasuraman, A. and Berry, L.L. (1985). Problems and strategies in services marketing. Journal of Marketing, 49, Spring, 33-46. 